\title{
Heat Transfer and Thermal Air Management in the Electronics and Process Industries
}

\author{
Harvey M. Thompson \\ Institute of Engineering Thermofluids, Surfaces \& Interfaces (iETSI) \\ School of Mechanical Engineering, University of Leeds, Leeds, \\ United Kingdom
}

\section{Introduction}

Rising energy costs and important legislative drivers are making the achievement of efficient heat transfer and thermal management of crucial importance in energy intensive industries. In the electronics industry, inexorable increases in microprocessor performance due to the use of multiple cores on a single chip are creating an enormous challenge for the cooling infrastructure, since almost all of the electrical energy consumed by the chip package is released as heat (Anandan \& Ramalingam, 2008). This is particularly relevant to the rapidly increasing number of large scale data centres, see Figure 1, which form the backbone of the digital society on which the world's population is becoming increasingly reliant. The power consumption of data centres is rising sharply, having doubled in the last five years and is likely to double again in the next five years to over 100 billion KWh (Scofield \& Weaver, 2008). These enormous energy requirements are presenting governments and industry with a serious energy supply problem (Shehabi et al., 2011) and the importance of data centres' energy efficiency has now been recognised at the international level with the formation of several industry consortia such as the Green Grid, the Uptime Institute and the Data Centre Alliance to promote energy efficiency and best practices in the data centre industry.

Since most enterprise data centres run significant quantities of redundant power and cooling systems to produce higher levels of resiliency, this had led to significant power consumption inefficiencies. The latter are exacerbated by the inefficiencies in the Information Technology (IT) hardware and cooling requirements, each accounting for roughly $40 \%$ of the total energy usage. This results in each KWh of energy for data processing requiring a further KWh for cooling (Almoli et al., 2011). In a typical data centre, electrical energy is drawn from the main grid to power an uninterruptible power supply (UPS) which then powers the IT equipment, supply power to offices and to power the cooling infrastructure: computer room air conditioning (CRAC) units, building chilled water pumps and water refrigeration plant. The IT load inefficiencies can be improved by server virtualisation and improved semi-conductor technologies, while the chiller plant is 
generally the biggest energy cooling component and increasing the set point temperature of the chilled water leaving the chiller evaporator offers significant potential reductions in the overall cooling plant energy consumption.

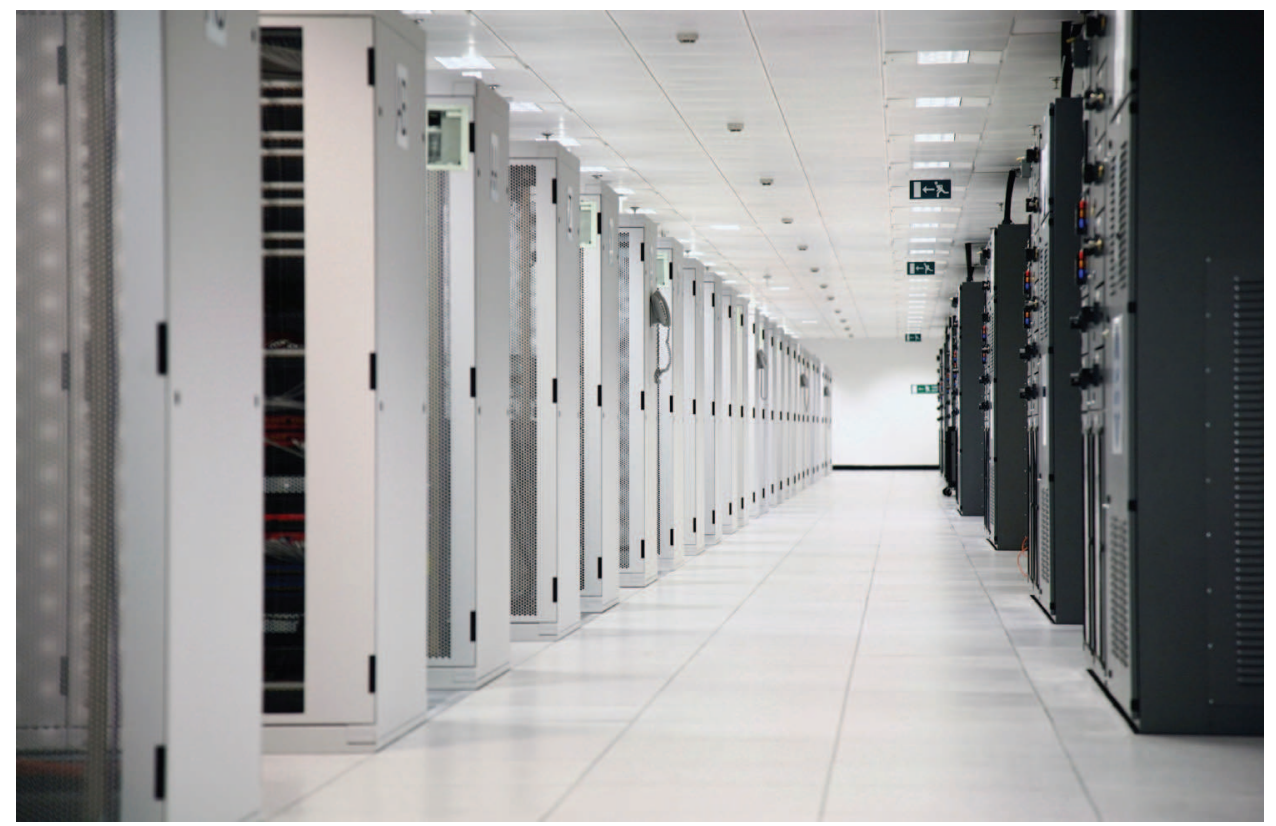

Fig. 1. A large scale data centre with several rows of server racks

A key strategy for efficient thermal air management in a data centre, as recommended in the EU Code of Conduct on Data Centre Energy Efficiency, is to separate hot and cold air via a layout of alternating hot and cold aisles (Rasmussen, 2006; Niemann, 2008). These are shown schematically in Figure 2. In the cold aisle containment strategy, cold air is supplied from the CRAC units through floor tiles or diffusers into cold aisles and the racks are arranged so that all server fronts/intakes face cold aisles. This counteracts the problem that arises if all rows are arranged with intakes facing the same way, when equipment malfunction is inevitable due to server overheating (Cho et al., 2009). In the hot aisle containment strategy, it is the hot air that is contained and this approach can have advantages in terms of obviating the need for raised floor tiles and providing hotter air to the CRAC units, increasing their overall efficiency of performance. The importance of good air flow management in data centres has led to increasing use of Computational Fluid Dynamics (CFD) (Versteeg \& Malalasekera, 1995) to design data centre operations to ensure the thermal environment within data centres conforms to narrow, acceptable bands. Care must, however, be taken to ensure that CFD predictions are properly validated and the limitations of its key assumptions (for example on the coupling between the small-scale server air flows and the larger scale data centre air flows) are understood (Almoli et al., 2011). Once validated, CFD models can be very useful for data centre air flow management in enabling a large number of design scenarios to be investigated and optimal server rack configurations to be identified much more quickly than would be possible experimentally. 


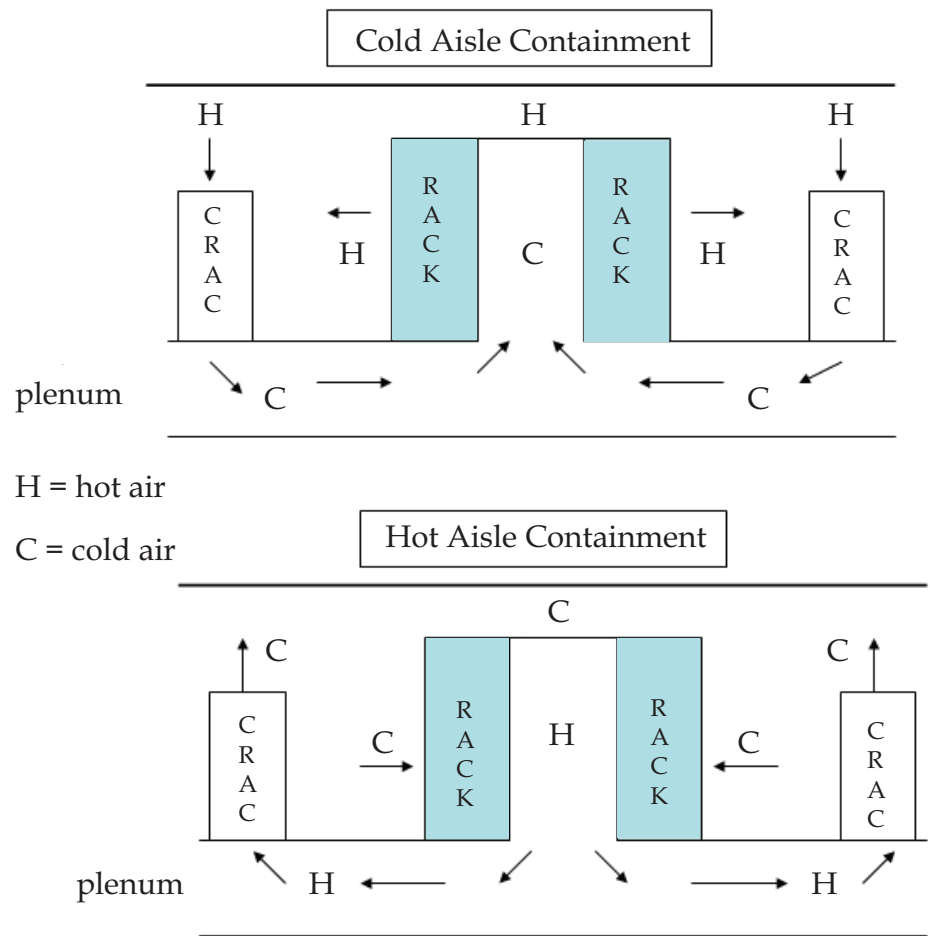

Fig. 2. Cold and hot aisle containment strategies

Relying on air as the primary heat transfer medium in data centres is becoming increasingly problematical due to inexorable increases in power densities in IT equipment. The reduced effectiveness of using air to cool servers is promoting much greater interest in a range of promising alternative technologies based on direct liquid loop cooling, such as dielectric liquid immersion and on-chip spray and jet impingement cooling (Garimella, 2000). This is because the higher heat capacities and associated heat transfer coefficients of liquids mean that they are much more efficient at transferring the waste heat, but with the disadvantages of requiring liquid loops as close as possible to the heat source. Some of the most promising liquid cooling technologies in electronics are discussed briefly in section 2 .

Energy consumption in the process industries is also currently an area where a significant amount of research is being conducted. Due to the enormous range of heat transfer technologies deployed in the process industries, this chapter focuses on one important heat transfer component of several industrial applications, namely the use of convective heat transfer from impinging air jets within industrial ovens (Martin, 1977; Sarkar \& Singh, 2004). These are used in applications ranging from the tempering of glass, drying of paper, textiles and precision coated products, to the cooling of metal sheets, turbine blades and, indeed, electronic components, as well as several examples in the food processing and baking industries. Forced-convection ovens in the coating, converting and baking industries typically use arrays of hot air impingement jets to transfer heat into products in order to, in the former cases, vaporise their solvent components, and in the latter cases to bake important food products such as bread, see Figure 3. 


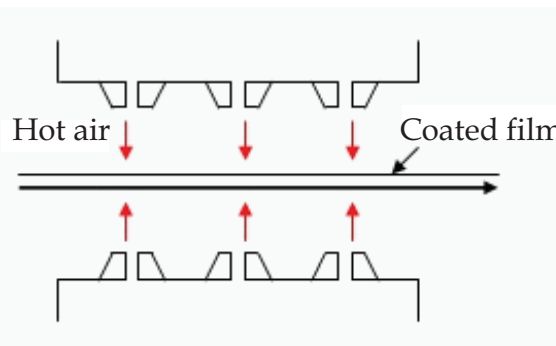

(a)

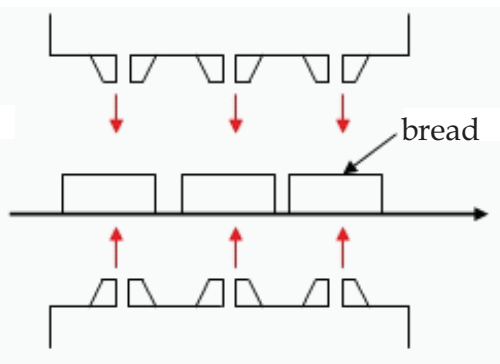

(b)

Fig. 3. Schematic diagram of forced-convection ovens using hot air impinging jets in the (a) coating and converting and (b) bread baking industry

In the coating and converting industries, drying capacity is often the key limitation on production speed and as a result high speed air jets (typically between 10 and $100 \mathrm{~m} / \mathrm{s}$ ) are used to increase the heat transfer coefficients and hence heat transfer into the coatings (Martin, 1977). This in turn leads to greater problems with surface disturbances when drying air emerges from an array of nozzles arranged perpendicular to the machine direction and disturbs the surface of the wet coating. A recent study into surface disturbances in multilayer coated products has shown how carefully redistributing solvent so as to increase the viscosity of the upper layers can significantly improve robustness to drying-air induced disturbances, leading to important commercial benefits in terms of reduced drying load and increased drying rates (Ikin \& Thompson, 2007).

Baking is also a complex process of simultaneous heat, water and water vapour transport within the product where the heat is supplied by a variety of indirect-fired and direct-fired forced convection ovens (Zareifard et al., 2006). Indirect ovens rely on radiation from heated elements within an oven, whereas forced convection ovens are now increasing in popularity since they can offer greater levels of thermal efficiency (Khatir et al., 2011). In the bread baking industry, the primary concern is the effect of heat transfer on the final product quality, which is influenced by the rate and amount of heat application, the temperature uniformity and humidity levels in the baking chamber and the overall baking time (Zhou \& Therdthai, 2007). Temperature distribution is particularly important since it affects the enzymatic reaction, volume expansion, gelatinization, protein denaturation, non-enzymatic browning reaction and water migration. The timing and application is also very important since supplying too high a temperature can cause early crust formation and a shrunken loaf. Forced convection ovens in the baking industry transfer heat to the product by convection from the surrounding air, radiation from the oven walls to the product surfaces and conduction from its containers. The relative importance of convection and radiation is determined by the baking temperatures and the speeds of the impinging jets; for low air speeds $(\sim 1 \mathrm{~m} / \mathrm{s})$ radiation is the predominant mode while convection is much more important for higher air speeds (Boulet et al., 2010). Most previous studies in the bread baking industry have tended to focus on regimes with relatively low air speeds, where radiative heat transfer is most influential (Kocer et al., 2007), although high air speeds are now receiving greater attention in the literature.

For many years the design and control of baking ovens relied on empirical models, correlating overall performance with simple global parameters such as chamber volume, the 
temperature of the heating elements and inlet conditions (Carvalho \& Nogueira, 1997). However, the increasing need to reduce energy consumption during baking has led to far greater use of sophisticated mathematical models in order to optimise baking conditions. These include models of the internal temperature and moisture conditions inside the dough/bread (Zheleva \& Kambourova, 2005) and several analyses based on Computational Fluid Dynamics, which predict the velocity and temperature distributions within baking chambers. Recent studies by Zhou \& Therdthai (2007) and Norton \& Sun (2007) have shown how a baking oven's energy consumption can be reduced by manipulating airflow patterns so as to increase the volume of airflow while reducing the energy supplied. CFD models can also provide valuable insight into key baking issues that influence product quality, such as temperature uniformity, that are difficult to measure experimentally.

This chapter presents a brief review of some of the key thermal management challenges in the electronic and process industries that are being addressed by current research projects both at the University of Leeds and at other institutions. In the electronics industry, the focus is on the rapidly burgeoning data centres industry, where efficient thermal air management is crucial. The current role, capabilities and limitations of CFD modelling in this sector are discussed, as are the promising future liquid cooling technologies that will be increasingly needed as the limits of air cooling methods are reached. In the process industries, the particular focus is on the challenges of improving the energy efficiency of forced convection ovens used throughout the coating, converting and bread baking industries. The key role of CFD modelling in improving oven design and operation is discussed, together with a brief overview of the future experimental and computational research needed to embed computational design methods into industrial practice.

\section{Heat transfer and thermal airflow management in data centres}

\subsection{Air cooling management}

As discussed above, currently most data centre cooling is achieved using cold air supplied by CRAC units into data centres through raised floor tiles that then passes through the server racks, cools the electronic equipment and emerges from the back of the servers as a hot air stream, see Figure 2. Maintaining temperature and humidity design conditions is critical to the good operation of data centres and generally temperature conditions at the inlet to the racks should be maintained between $20-30^{\circ} \mathrm{C}$ and $40-55 \%$ relative humidity in order to prevent equipment malfunction (Cho et al., 2009). Recent figures from the ASHRAE trends in rack heat load shows typical server heat fluxes of $27 \mathrm{KW}$ for a 19 inch rack (Shrivastava et al., 2009) and these will be even larger today.

The European Commission has created an EU Code of Conduct in response to increasing energy consumption in data centres and the need to reduce the related environmental, economic and energy supply security impacts. The Code of Conduct aims to achieve this by improving understanding of energy demand within a data centre, raising awareness and recommending energy efficiency best practice and targets. The Code of Conduct makes several important recommendations for air flow management in data centres in order to improve overall energy efficiency. A key recommendation is that the hot/cold aisle layout should be implemented which aims to minimise the amount of bypass air, which returns to CRAC units without performing cooling, and the amount of mixing of cold and hot air which leads to higher air intake temperatures into servers. As shown in Figure 2 the hot/cold aisle concept aligns equipment airflow to create aisles between racks that are fed 
cold air from which the electronic equipment draws intake air in conjunction with hot aisles to which all equipment exhausts hot air.

Although the cold air containment strategy is probably the most common today, the alternative approach, termed hot-aisle containment, is also increasing in popularity (Niemann, 2008). In this approach the hot air from the servers is contained and is cooled before being recirculated back into the room. Key advantages of this approach that have been proposed include:

- it does not impact on surrounding data centre infrastructure and obviates the need for raised floor tiles

- it enables return air to be returned to CRAC units at higher temperatures, enabling the chillers to operate more efficiently and increase the proportion of the year during which free cooling technologies (where no compressor is required) can be utilised.

- reduced humidification and de-humidification costs, saving energy and water.

There are currently conflicting opinions about which containment strategy is the best in practice, however maximising the use of free cooling is another key recommendation of the EU Code of Conduct. Other key thermal air management recommendations of the Code of Conduct include:

- the use of blanking plates where there is no electronic equipment in order to prevent cold air passing through gaps in the rack;

- installing aperture brushes to cover all air leakage opportunities provided by floor openings at the base of racks and gaps in their sides;

- use of overhead cabling to prevent obstructions in air flow paths that increase the fan power needed to circulate air throughout the data centre.

In addition to encouraging imaginative use of the waste heat produced in data centres, such as using the low grade heat for buildings and swimming pools, the ability to control the thermal air environment in data centres more accurately enables the chilled water set point temperature to be increased, maximising the use of free cooling and reducing compressor energy consumption significantly.

\subsection{CFD modelling of thermal air flows in data centres}

Computational Fluid Dynamics (CFD) is now frequently used to design the layout of servers within data centres. Thermal air flows in data centres are complex, recirculating air flows characterised by multiple length scales, modes of heat transfer and flow regimes. Length scales range from processor length scales (order of $\mathrm{mm}$ ) to rack length scales (of the order of metres) up to data centre length scales (order of several metres). A typical Reynolds number, $\mathrm{Re}$, based on a typical air inlet velocity from supply vents of $1 \mathrm{~m} / \mathrm{s}$ and a rack length scale of $2 \mathrm{~m}$ leads to an estimated $\mathrm{Re} \approx 10^{5}$ indicating the turbulent flow regime (Almoli et al., 2011). However, as discussed by Choi et al. (2008), for the flow through servers racks the Reynolds numbers are typically much smaller and may even lie within the challenging laminarturbulent transition regime which requires different flow models from those that can be used at the data centre length scales for fully developed turbulent conditions. At present there is no effective multi-scale CFD model that integrates the thermal circuit modelling of microprocessors and data centre scale thermal flow modelling and which is capable of adapting to dynamic conditions within data centres.

However, most previous CFD studies of data centre airflows have simply assumed the flow outside the racks is fully turbulent and have used Reynolds Averaged Navier Stokes (RANS) flow models, see e.g. Cho et al. (2009), while modelling the racks in a compact 
manner without explicit representations of internal components. These are based on the following governing continuity and momentum equations, written in RANS format as

$$
\begin{gathered}
\nabla \cdot \underline{U}=0 \\
\frac{\partial \underline{U}}{\partial t}+\nabla \cdot(\underline{U} \underline{U})=\frac{1}{\rho} \nabla \cdot\left(\underline{\underline{\sigma}}-\rho \underline{\underline{U}^{\prime} \underline{U^{\prime}}}\right)+\frac{1}{\rho} \underline{S}
\end{gathered}
$$

where $\underline{\underline{\sigma}}=-P \underline{\underline{I}}+\mu\left(\nabla \underline{U}+(\nabla \underline{U})^{T}\right)$ is the Newtonian stress tensor, $\mu$ is the air viscosity, $\rho$ its density, $\underline{U}$ and $\underline{\underline{U}}$ are the average and turbulent fluctuation velocity vectors respectively, $\mathrm{P}$ is the pressure and $\underline{I}$ the unit tensor. The vector $\underline{S}$ represents the additional momentum sources, which are discussed below, and the $-\rho \underline{\underline{U}^{\prime} \underline{\underline{U}}}$ term is the Reynolds stress tensor that requires additional model equations.

Most CFD models of data centre airflows use the standard k- $\varepsilon$ model (Cho et al., 2009) where the turbulence is modelled in terms of the turbulent kinetic energy (k) and turbulent dissipation $(\varepsilon)$. The two additional transport equations for the $\mathrm{k}-\varepsilon$ model are:

$$
\begin{gathered}
\frac{\partial k}{\partial t}+\nabla \cdot(k \underline{U})=\frac{1}{\rho} \nabla \cdot\left(\frac{\mu_{t}}{\rho_{k}} \nabla k\right)+\frac{2 \mu_{t}}{\rho} S_{i j} S_{i j}-\varepsilon \\
\frac{\partial \varepsilon}{\partial t}+\nabla \cdot(\varepsilon \underline{U})=\frac{1}{\rho} \nabla \cdot\left(\frac{\mu_{t}}{\rho_{\varepsilon}} \nabla \varepsilon\right)+\frac{C_{1 \varepsilon} \varepsilon 2 \mu_{t}}{\rho k} S_{i j} S_{i j}-C_{2 \varepsilon} \frac{\varepsilon^{2}}{k}
\end{gathered}
$$

with the turbulent viscosity defined via $\mu_{t}=\rho C_{\mu} \frac{k^{2}}{\varepsilon}$, the $S_{i j}$ terms are the deformation tensor and the $\rho_{k}, \rho_{\varepsilon}, C_{1 \varepsilon}, C_{2 \varepsilon}$ and $C_{\mu}$ are five empirical constants (Boulet et al., 2010). The energy equation is also solved and takes the form

$$
\frac{\partial T}{\partial t}+\nabla \cdot(T \underline{U})=\nabla \cdot\left(\left(\frac{v}{\operatorname{Pr}}+\frac{v_{T}}{\operatorname{Pr}_{T}}\right) \nabla T\right)+\frac{1}{\rho C_{p}} S_{Q}
$$

where $\mathrm{T}$ and $\mathrm{v}$ are the temperature and dynamic viscosity respectively and Pr is the Prandtl number defined by

$$
\operatorname{Pr}=\frac{v}{\alpha} \text { where } \alpha=\frac{k}{\rho C_{p}},
$$

$\mathrm{k}$ is the thermal conductivity and $C_{p}$ is the air's specific heat capacity. The subscript $T$ indicates the turbulent flow and $\mathrm{S}_{\mathrm{Q}}$ is the source term of the energy equation, namely the heat generated by the processors.

Several commercial CFD codes have now been used to solve air flows in data centres, ranging from general purpose codes such as Ansys Fluent 12 (Almoli et al., 2011), to a number of codes specifically developed for the rapidly growing data centre industry; the latter include CFD software packages such as Flovent, Six Sigma and TileFlow which are 
designed for maximum ease of use. However, it is important to recognize that CFD is still largely unverified for data centre airflows (Shrivastava et al., 2009), and that a hierarchy of models is required for the data centre air flows and air flows through the racks. All CFD models of data centre air flows should ideally only be used after careful validation against experimental data.

The recent study by Almoli et al. (2011) noted that previous CFD studies of data centre air flows have provided very little explanation of the way the flow through server racks are modelled. This makes it very difficult to carry out meaningful comparisons with previous CFD studies. They proposed that an efficient coupling between the data centre air flows and air flow through the racks could be achieved by treating the racks as porous media. Their permeabilities can be estimated experimentally by measuring pressure drops across the rack for a range of flow rates and the rate of heat generation by the IT equipment can be estimated from manufacturer's specifications. They used this approach to develop the first CFD model for data centre cooling scenarios where a liquid loop heat exchanger is attached at the rear of server racks (back doors) which can avoid the need to separate the cold and hot air streams in traditional hot/cold aisle arrangements and can also significantly reduce the load on the CRAC units. This study also investigated the effectiveness of additional fans in the back door heat exchangers.

\subsection{Alternative liquid cooling techniques}

Relying solely on air as the primary heat transfer medium in data centres is becoming increasingly problematical due to inexorable increases in power densities from IT equipment. Since liquids have much higher heat capacities and heat transfer coefficients than gases, liquid cooling can potentially be much more effective than gas cooling for high power electronic components. However, until relatively recently problems with liquid cooling systems due to leakage corrosion, extra weight and condensation have limited their use to high power density situations where air cooling is simply not viable. As discussed in the recent review by Anandan \& Ramalingham (2008), a range of alternative liquid cooling technologies are now beginning to be taken up within industry. A selection of some of the most promising approaches is outlined briefly below.

\subsubsection{Dielectric liquid immersion cooling}

Here, electronic components are immersed in a dielectric fluid as shown schematically in Figure 4. This involves the boiling of the working fluid on a heated surface and is highly effective since the phase change from liquid to vapour increases the heat flux from the heated surface significantly and the high thermal conductivity of the liquid increases the accompanying convection. The main limitation of using these methods is the lack of suitable dielectric fluids, which are usually refrigerant-type fluids whose effectiveness can be limited by problems associated with the long term corrosion of computer components.

\subsubsection{Spray cooling}

In spray cooling, a cooling agent in form of jet of liquid droplets, is injected through nozzles onto the electronic module. The spray is formed by a pressure drop across the nozzle, impinges on the surface and forms a thin liquid film. The heat from the electronic module is dissipated by evaporating the cooling agent. The resultant hot liquid and vapour is recycled through a spray drain, as indicated in Figure 5. 


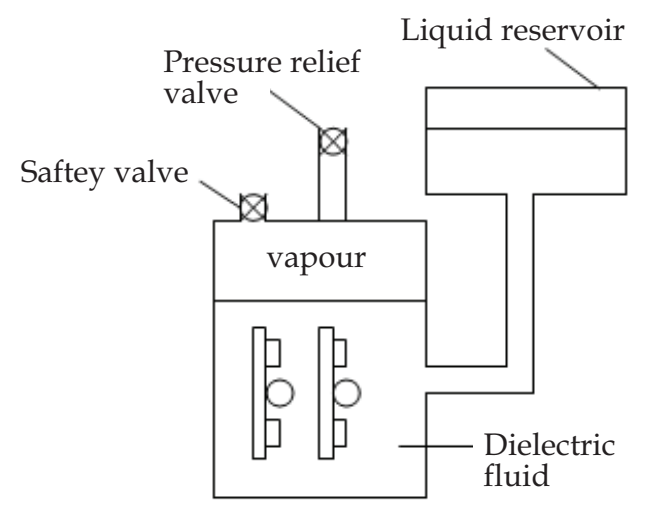

Fig. 4. Direct liquid immersion cooling

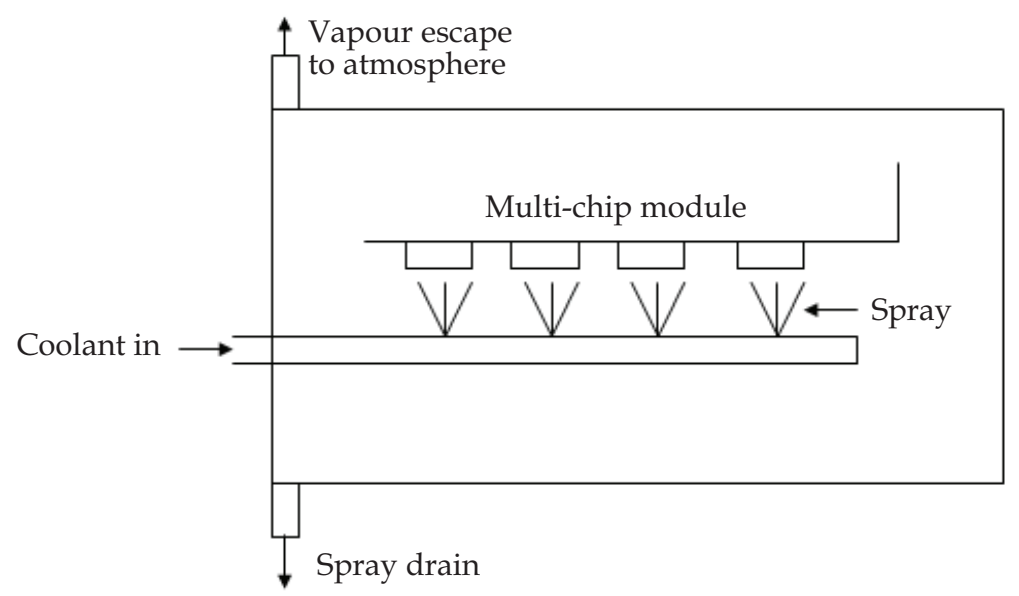

Fig. 5. Schematic diagram of the spray cooling approach

Spray cooling is a very promising cooling method for high heat flux applications (Mudawar, 2001). It has specific advantages since spraying the heat source directly eliminates the thermal resistance of the bonding layer in electronic equipment and offers attractive ratios of power supplied for cooling to rate of heat removal. An important limitation to the wider adoption of spray cooling is that these must be non-conducting, dielectric liquids. Water is often used when a thin protective, coated layer is applied to electronic equipment to reduce the risk of short circuits due to water's low dielectric strength. Relatively few alternative liquids have demonstrated their suitability for spray cooling applications (Chow et al., 1997).

\subsubsection{Indirect liquid cooling}

As the name suggests, in indirect cooling the liquid cooling agent does not have direct contact with the electronic module and instead a thermal pathway is formed between the module and the cooling agent, as shown in Figure 6. The thermal pathway is often a cold 
plate with high thermal conductivity and since there is no contact between the module and cooling agent, the latter can be any suitable liquid. The high thermal conductivity and environmental-friendliness of water make it the most common cooling agent, however foam-filled cold plates are increasingly being used for high heat flux cooling applications (Apollonov, 1999, 2000).

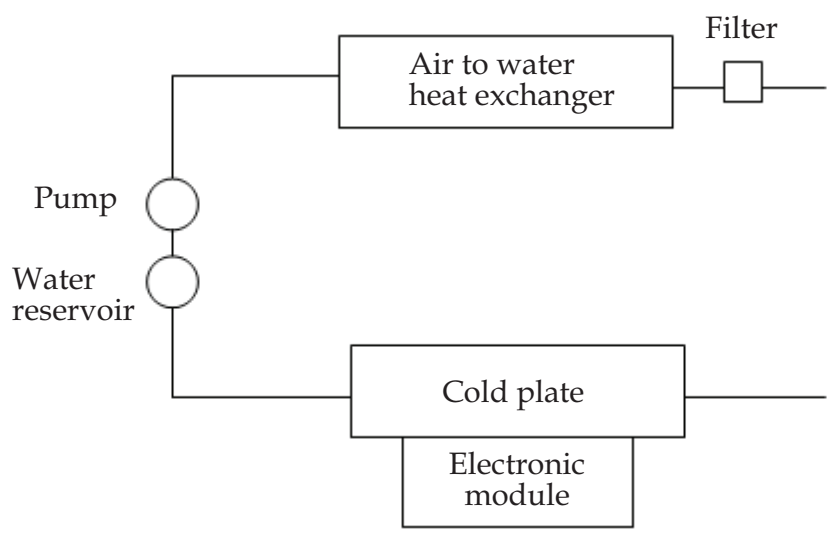

Fig. 6. Indirect cooling of electronic modules

\subsubsection{Liquid jet impingement cooling}

Many applications in industry require localised cooling and use impinging liquid jets to achieve this objective. Important examples include the cooling of metal sheets, turbine blades and high power density electronic components. In electronic cooling, cold liquid jets are typically directed towards a surface from which heat needs to be removed. Figure 7 shows schematic diagrams of common approaches to electronic cooling using impinging liquid jets (Anandan \& Ramalingham, 2008). These can be classified into free-surface, submerged and confined submerged jets (Wolf et al., 1993).

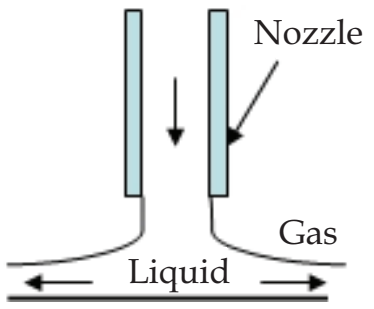

(a)

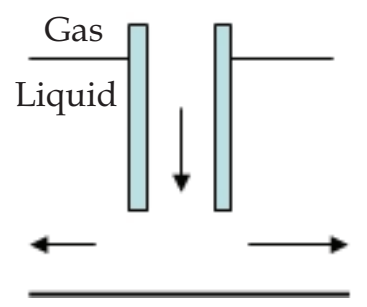

(b)

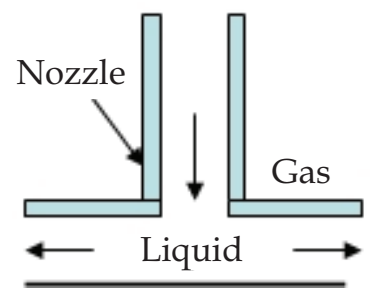

(c)

Fig. 7. Jet impingement configurations: (a) free-surface jet, (b) submerged jet, (c) confined submerged jet

Impinging liquid jets typically have large heat transfer coefficients immediately below the point of impact and rapidly decay away from the point of impact. This variation in heat transfer coefficient needs to be borne in mind when impinging liquid jet cooling is being considered for specific applications (Sarkar \& Singh, 2004). 


\section{Impinging jet heat transfer in the process industries}

In contrast to the application of impinging jets of cold liquid to cool products, hot air impingement jets are widely used in process industries to transfer energy into a variety of products. They are used, for example, to dry coated products, paper and textiles (Ikin \& Thompson, 2007), or to bake a wide variety of food products (Norton \& Sun, 2006), by directing hot air jets towards a target product in order to transfer energy into it. The effect of parameters such as jet velocity, jet diameter, nozzle to chip spacing, nozzle geometry, turbulence level and fluid properties on the effective heat transfer coefficients have been reviewed in detail by several authors, see for example Martin (1977), Webb \& Ma (1995), Lienhard (1995) and Garimella (2000).

These have revealed that the flow patterns from impinging air jets have 3 characteristic regions, as shown in Figure 8 below, namely the free-jet, impingement/stagnation flow and wall-jet regions (Olsson \& Trägårdh, 2007). The free-jet region has also been categorised into 3 sub-regions: the potential core, developing flow and developed flow ones. In practice, there is a wide variation in the heat transfer coefficient, which decays from its maximum value in the stagnation point region, and jets with $6 \leq \mathrm{H} / \mathrm{D} \leq 8$ are found to be ideal from a heat transfer perspective because they ensure that the potential core is fully decayed but without excessive energy dissipation associated with very long jets. The actual optimal value of H/D does, however, depend on the transition effect and the induction of turbulence in the jet wake. Lyttle \& Webb (1994), for example, showed that increased turbulence with small plate separations leads to significantly increased local heat transfer.

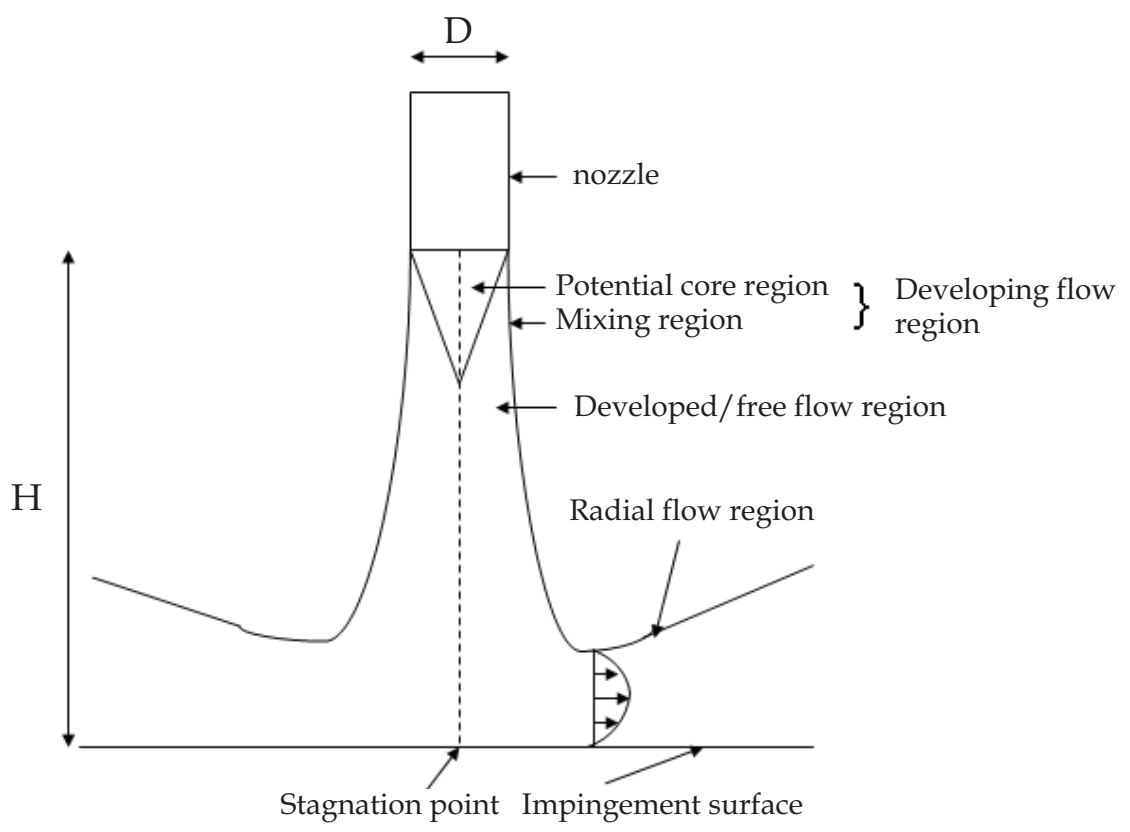

Fig. 8. Flow structure in an impinging air jet 
Martin (1997) provided an early, very comprehensive survey of heat and mass transfer from impinging jet flow. He found that heat transfer conditions can generally be described in dimensionless form, where the Nusselt number is a function of the flow Reynolds and Prandl numbers and of the geometrical variables. In these expressions, the appropriate characteristic length is the hydraulic diameter of the nozzles, $S$, and the Reynolds number is formed by mean velocity at the nozzle exit, calculated from the total mass flow rate. For single round and slot nozzles, the mean heat transfer coefficient may be described in dimensionless form by an average Nusselt number of the form

$$
\overline{\mathrm{Nu}}=\mathrm{F}(\mathrm{Re}, \mathrm{Pr}, \mathrm{r} / \mathrm{D}, \mathrm{H} / \mathrm{D})
$$

where $r$ is the distance from the stagnation point. For a single round nozzle, this was found to take the particularly simple form

$$
\overline{\mathrm{Nu}}=0.5 \operatorname{Re}^{2 / 3} \operatorname{Pr} 0.42
$$

In a wide variety of forced convection ovens in the process industries the hot air jets emerge from an array of nozzles arranged perpendicular to the machine direction and transfer heat into the target products by convection from the hot air jets, radiation from the oven walls and conduction from its containers, see Figure 3 above.

\subsection{The coating and converting industries}

In the coating and converting industries, forced convection ovens typically use hot air impingement jets in order to supply the energy needed to vaporise the solvent components and hence dry the coated products. In such systems, drying capacity is often the key limitation on production speed and as a result high speed air jets (typically between $10 \mathrm{~m} / \mathrm{s}$ and $100 \mathrm{~m} / \mathrm{s}$ ) are used to increase the heat transfer coefficients and hence heat transfer into the coated products. However, the aggressive drying due to high air speeds can lead to practical quality problems due to surface non-uniformities in coating systems. One such problem is due to the too rapid depletion of solvents near the surface of the coating which leads to skin formation which can prevent subsequent solvent transport out of the surface of the coated film. This problem can usually be alleviated by using less aggressive drying in the front zones of the drying ovens while the viscosity of the coating increases due to solvent depletion.

Another important problem is particularly prevalent during the manufacture of high quality, multi-layer coatings, where drying air induced disturbances to the free surface of coated films can destroy product quality. A recent study into coated product robustness to drying-air induced disturbances has shown that an effective strategy to overcome this problem is to redistribute solvent from the upper layers to the lower layers so that the uppermost layers are more viscous and hence resistant to drying-air induced disturbances (Ikin \& Thompson, 2007). For products where this redistribution of solvent is not possible, for example in the wide variety of single-layer coating systems, alternative hot air jet drying methods may be preferable. One such method is shown in Figure 9, the so-called air floatation drying approach (Noakes et al., 2002) where the product is dried by the hot air issuing from air floatation nozzles, arranged above and below the coated web. In this approach the main difficulty is to arrange the nozzles so that they produce a stable, sinusoidal web profile, however this can provide effective drying for high quality, highly sensitive industrial coatings. 


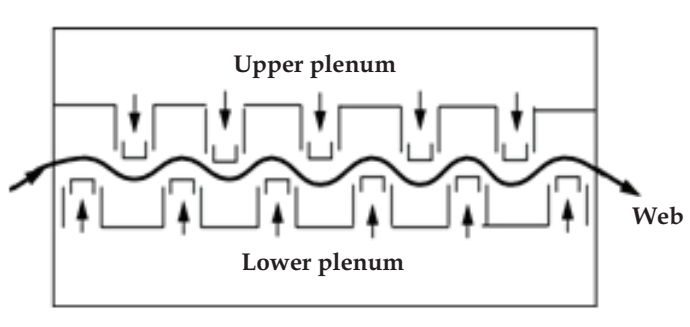

(a)

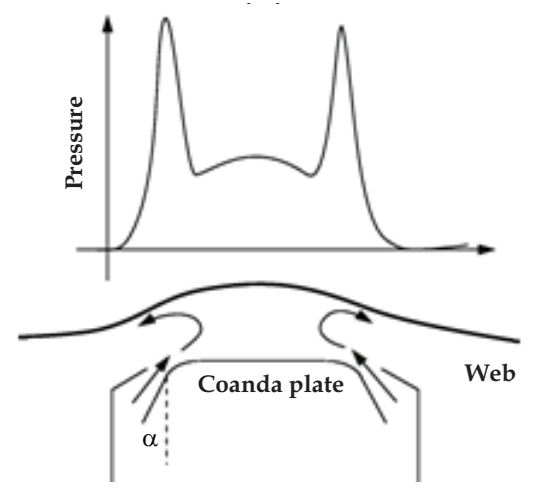

(b)

Fig. 9. Industrial air floatation drying: (a) stable web configuration and (b) typical pressure profile under each floatation nozzle

\subsection{The bread baking industry}

Baking is a complex process of simultaneous heat, water and water vapour transport within the product, where heat is supplied by a variety of indirect-fired and direct-fired forced convection ovens (Zareifard et al., 2006). Indirect ovens rely on radiation from heated elements within the oven, whereas forced convection ovens heat the product by convection from hot air impinging jets, radiation from the oven walls, and conduction from its containers. During baking it is very important to control the temperature distribution and uniformity throughout the oven since this dominates product quality due to its effect on the enzymatic reaction and water migration. The timing of the application of temperature is also very important since supplying too high a temperature can cause early crust formation and shrunken bread loaves.

For many years the design and control of baking ovens relied on empirical models, correlating overall performance with simple global parameters such as chamber volume, the temperature of heating elements and inlet conditions (Carvalho \& Nogueira, 1997). However, since roughly half of the energy use in a bakery is consumed in the baking oven (Thumann \& Mehta, 2008), the need to reduce energy consumption in the baking industry has led to a particular focus on developing better scientific understanding and control of this important aspect of baking processes. This in turn has led to far greater use of mathematical modelling to optimise baking predictions by predicting, for example, crust thickness as a function of operating conditions or the internal dough/bread, temperature and moisture conditions during baking (Zheleva \& Kambourova, 2005). Until recently, previous scientific studies in the bread baking industry have tended to focus on regimes with relatively low air speeds $(<1 \mathrm{~m} / \mathrm{s})$, where radiative heat transfer is most influential (Kocer et al., 2007). However, forced convection ovens with higher air speeds now appear to be gaining in popularity since they can offer greater levels of thermal efficiency (Khatir et al., 2011).

\subsubsection{CFD modelling of thermal air flows in bread baking ovens}

CFD modelling is now being increasingly applied to a wide range of different food processes in order to improve product quality and reduce operating costs (Norton \& Sun, 
2006). Several CFD models of the thermal airflows in forced convection baking ovens have appeared recently (Zhou \& Therdthai, 2007) which predict the air velocity and temperature distributions within baking ovens. However, since the thermal airflows in baking ovens are highly complex, recirculating flows the choice of an appropriate turbulence model and proper experimental validation of its predictions are essential. Most previous CFD studies of forced convection baking ovens have used Reynolds Averaged Navier-Stokes (RANS) turbulence closure equations in baking applications, including the standard $k-\varepsilon$ model (Norton and Sun, 2006, 2007) and the realizable k- $\varepsilon$ model for flow in complex geometries (Boulet et al., 2010). Far fewer CFD studies on ovens with high speed impinging air jets have appeared to date, however reasonable agreement between CFD predictions of temperature distribution and experiments has been reported recently (Khatir et al., 2011). These CFD studies have shown that reduced overall energy consumption can be achieved by control strategies based on heat flux into the bread rather than simply controlling the air temperatures. For example it is possible to reduce energy consumption for particular baking temperature profiles by increasing the volume of airflow whilst reducing the heat supplied to the oven. CFD models have also been used to study how operating conditions can be adjusted to achieve the optimum temperature profile since increasing temperature uniformity in baking ovens is known to lead to better quality baked products. These are now being integrated with other mathematical models of quality attributes to estimate weight loss from, and the crust colour of, the bread.

One important issue that has not been addressed satisfactorily so far in CFD studies is the choice of the most appropriate length-scale for thermal air flows in forced convection ovens. This is usually based on a typical oven length scale, leading to Reynolds numbers well within the turbulent flow regime. However, in light of the rapid flow transition shown in Figure 8, a more appropriate length scale may be that based on a typical nozzle width (of the order of $\mathrm{mm}$ ) which can reduce the effective Reynolds number significantly and may even take the flow into the complex laminar-turbulent regime. At the very least the assumption of fully turbulent flow to justify the use of $k-\varepsilon$ models needs to be verified experimentally by a comprehensive programme of measurements of the airflow velocities, temperatures and heat fluxes under practical operating conditions. At present no such comprehensive experimental database exists.

Finally, note that if the maximum practical benefit for the baking industry is to be derived from CFD models, these will need to be incorporated into formal design optimization frameworks that enable physically meaningful objective functions to be minimised. Recent steps in this direction have been taken (Hadiyanto et al., 2008, 2009; Purlis, 2011), however much more progress still needs to be made in embedding these approaches into industrial oven design and operational practice.

\section{Conclusions}

The achievement of efficient heat transfer and thermal air management is becoming increasingly important in all energy intensive industries. The electronics industry now faces major challenges to provide the cooling required by the rapidly expanding data centres that form the backbone of the digital society and which produce enormous quantities of waste heat that must be managed efficiently. The seriousness of this problem and the importance of improving the energy efficiency of data centres has been recognised by the formation of several industry-led consortia and governmental initiatives. At present the majority of data 
centre cooling is achieved through recycling cold air through server racks and CFD is now an integral means of improving thermal air flow management in data centres. Despite having achieved several successes there are still important areas of weakness of current CFD methods and a need for greater transparency in terms of describing the all-important boundary conditions and greater access to validation case study data.

The energy consumption of process industries is also receiving greater attention in the scientific literature. This chapter has focussed on one important aspect of this enormous subject, namely convective heat transfer from impinging air jets in forced convection ovens used in the coating, converting and bread baking industries. Advances in CFD methods are now being exploited within these industries and have shown, for example, how the required heat flux into products can be achieved more efficiently by optimising the air flow velocity and temperature conditions. Outstanding issues for the CFD modelling of these systems include the variation of turbulence levels throughout the oven, the validity of popular turbulence models used to model them and, once again, the need for a comprehensive database of experimental data for validation purposes. In order for industry to derive the maximum benefit from the improving capabilities of CFD modelling, CFD models will need to be incorporated into formal design optimization frameworks that are capable of minimising physically meaningful objective functions.

\section{Acknowledgements}

The author would like to thank several colleagues at the University of Leeds for their contribution and support. Thanks are particularly due to Dr Nikil Kapur, Dr Jon Summers, Dr Malcolm Lawes, Professor Phil Gaskell and Professor Vassili Toropov, to industrial collaborators: Airedale International Air Conditioning Ltd, Spooner Industries Ltd and Warburton's Ltd and the UK's Engineering and Physical Sciences Research Council (EPSRC) for financial support in these research areas.

\section{References}

Almoli, A; Thompson, A., Kapur, N., Summers, J.L, Thompson, H.M. \& Hannah, G. (2011). Computational Fluid Dynamic Investigation of Liquid Rack Cooling in Data Centres, to appear in Applied Energy, available from: doi:10.1016/j.apenergy.2011.02.003

Anandan, S.S. \& Ramalingam, V. (2008). Thermal management of electronics: a review of literature, Thermal Science, vol. 12, no. 2, (April 2008), pp 5-26, ISSN 0354-9836.

Ansys Inc. Ansys Fluent 12, 18th April 2011, Available from: http://www.ansys.com/Products/Simulation+Technology/Fluid+Dynamics/AN SYS+FLUENT/

Apollonov, V.V. (1999). Intensification of heat transfer in high-power laser diode bars bymeans of a porous metal heat-sink, Optics Express, vol. 4, pp 27-32, (June 1999), ISSN 1094-4087.

Apollonov, V.V. (2000). Highly efficient heat exchangers for laser diode arrays, Proceedings of SPIE, vol. 3889, pp 71-81, ISBN 1094-4087, Osaka, Japan.

Boulet, M; Marcos, B., Dostie, M \& Moresoli, C. (2010). CFD modeling of heat transfer and a flow field in a bakery pilot oven, J. Food Engineering, vol. 97, no. 3, (June 2010), pp 393-402, ISSN 0260-8774. 
Carvalho, M. \& Nogueira, M. (1997). Improvement of energy efficiency in glass-melting furnace, cement kilns and baking ovens, Applied Thermal Engng., vol. 17, nos. 8-10, (Aug-Oct 1997), pp 921-933, ISSN 1359-4311.

Cho, J; Lim, T. \& Sean Kim, B. (2009). Measurements and predictions of the air distribution systems in high compute density (Internet) data centers, Energy \& Buildings, vol. 41, (October 2009), pp 1107-1115, ISSN 0378-7788.

Choi, J; Kim, Y., Sivasubramaruam, A., Srebric, J., Wang, Q. \& Lee. J. (2008). A CFD-based tool for studying temperature in rack-mounted servers, IEEE Transactions on Computers, vol. 57, no. 8, (August 2008), pp 1129-1142, ISSN 0018-9340.

Chow, L.S., Sehemby, M.S. \& Pais, M.R. (1997). High-heat-flux spray cooling, Annual Review of Heat Transfer, vol. 8, (January 1997), pp 291-318, ISSN 0970-9991.

Data Centre Alliance. 18 ${ }^{\text {th }}$ April 2011, Available from: http://www.datacentrealliance.org

European Commission, EU Code of Conduct on Data Centres Energy Efficiency, version 2.0, 18th April 2011. Available from: http://ec.europa.eu/dgs/jrc/index.cfm?id=1410\& obj_id=6260\&dt_code=NWS\&lang $=$ en 0 .

Future Facilities, Six Sigma, 19th April 2011, Available from: http://www.futurefacilities.com/software/room/6SigmaRoom.php

S.V. Garimella (2000). Heat transfer and flow fields in confined jet impingement, Ann. Rev. Heat Transfer, vol. 10, (January 2000), pp 413-449, ISSN 1049-0787.

Green Grid, 18 th April 2011. Available from: http://www.thegreengrid.org

Hadiyanto, H; Esveld, D.C., Boom, R.M., Van Straten, G. \& Van Boxtel, A.J.B. (2008). Control vector parametrization with sensitivity based refinement applied to baking optimization, Food and Bioproducts Processing, vol. 86, no. 2, (June 2008), pp 130-141, ISSN 0960-3085.

Hadiyanto, H; Boom, R.M., Van Straten, G., Van Boxel, A.J.B. \& Esveld, D.C. (2009). Multiobjective optimization to improve the product range of baking systems, Journal of Food Process Engineering, vol. 32, no. 5, (October 2009), pp 709-729, ISSN 0145-8876.

Ikin, J.B. \& Thompson, H.M. (2007). Drying-air induced disturbances in multi-layer coating systems, Chemical Engineering Science, vol. 62, no. 23, (December 2007), pp 66316640, ISSN 0009-2509.

Innovative Research Inc., Tileflow, April 19th 2011, Available from: http://inres.com/products/tileflow/overview.html

Khatir, Z; Paton, J., Thompson, H.M., Kapur, N., Toropov, V.V., Lawes, M. \& Kirk, D. (2011). Computational Fluid Dynamics (CFD) Investigation of air flow and temperature distribution in a small scale bread baking oven, to appear in Applied Energy, Available from: doi:10.1016/j.apenergy.2011.02.002.

Kocer, D; Nitin, N. \& Karwe, M. (2007). Applications of CFD in Jet Impingement Oven, in: Da-Wen Sun (Ed.), Computational Fluid Dynamics in Food Processing, CRC Press, pp. 469-485, ISBN 978-0-8493-9286-3, retrieved from http://www.crcnetbase.com/isbn/9781420009217

Lienhard, J.H., (1995). Liquid jet impingement, Annual Review of Heat Transfer, vol. 6, (January 1995), pp 199-270, ISSN 1049-0787.

Lyttle, D. \& Webb, B.W. (1994). Air impingement heat transfer at low nozzle spacings, Int. J. Heat Mass Transfer, vol. 37, no. 12, (August 1994), pp 1687-1697, ISSN 0017-9310.

Martin, H. (1977). Heat and mass transfer between impinging gas jets and solid surfaces, Advances in Heat Transfer, vol. 13, (March 1977), pp 1-60, ISBN 0120200139. 
Mentor Graphics, Flovent, 18th April 2011, Available from: http://www.mentor.com/products/mechanical/products/flovent

Mudawar, I. (2001). Assessment of high-heat flux thermal management schemes, Trans. Components and Packaging Technologies, vol. 24, no. 2, (April 2001), pp 122-141, ISSN 1521-3331.

Niemann, J; (2008). APC White Paper \#135, Hot Aisle vs. Cold Aisle Containment, 19th April 2011, Available from: www.apcmedia.com/salestools/DBOY-7EDLE8_R0_EN.pdf

Noakes, C.J.; Thompson, H.M., Gaskell, P.H., Lowe, S. \& Osborn, M. (2002). Heat transfer characteristics of air flotation dryers, Paper Technology, vol. 43, no. 10, (October 2002), pp 46-50, ISSN 0958-6024.

Norton, T. \& Sun, D-W. (2006). Computational fluid dynamics (CFD) - an effective and efficient design and analysis tool for the food industry: A review. Trends in Food Science E Technology, vol. 17, no. 11, (November 2006), pp 600-620, ISSN 0924-2244.

Norton, T. \& Sun, D-W. (2007). An overview of CFD Applications in the Food Industry, in: Da-Wen Sun (Ed.), Computational Fluid Dynamics in Food Processing, CRC Press, pp. 1-41, ISBN 0849392861, retrieved from http://www.crcnetbase.com/isbn/9781420009217

Olsson, E.M. \& Trägårdh, C. (2007). CFD Modeling of Jet Impingement during Heating and Cooling of Foods, in: Da-Wen Sun (Ed.), Computational Fluid Dynamics in Food Processing, CRC Press, pp. 487-503, ISBN 0849392861, retrieved from http://www.crcnetbase.com/isbn/9781420009217

Purlis, E. (2011). Bread baking: technological considerations based on process modeling and simulation, Journal of Food Engineering, vol. 103, no. 1, (March 2011), pp 92-102, ISSN 0260-8774.

Rasmussen, N. (2006). Implementing Energy Efficient Data Centers, APC White Paper\#114, 19th April 2011, Available from: www.apcmedia.com/salestools/NRAN-6LXSHX_R1_EN.pdf

Sarkar, A. \& Singh, R.P. (2004). Air impingement technology for food processing: visualization studies, Lebens. Wiss. U. Tech., vol. 37, no. 8, (December 2004), pp 873879, ISSN 0023-6438.

Scofield, C.M. \& Weaver, T.S. (2008). Data center cooling using wet-bulb economizers, ASHRAE Journal, vol. 50, (August 2008), pp 52-58, ISSN 00012491.

Shehabi, A.; Masanet, E., Price, H., Horvath, A. \& Nazaroff, W.W. (2011). Data center design and location: consequences for electricity use and greenhouse-gas emissions, Building and Environment, vol. 46, no. 5, (May 2011), pp 990-998, ISSN 0360-1323.

Shrivastava, S.K.; Iyengar, M., Sammakia, G., Schmidt, R. \& VanGilder, J.W. (2009). Experimental-numerical comparison for a high-density data center: hot spot heat fluxes in excess of $500 \mathrm{~W} / \mathrm{ft}^{2}$, IEEE Transactions on Components and Packaging Technologies, vol. 32, no. 1, (January 2009), pp 166-172, ISSN 1521-3331.

Thumann, A \& Mehta, D.P. (2008). Handbook of energy engineering, Fairmont Press, ISBN 0881735817, Boca Raton, USA.

Uptime Institute, 19th April 2011, Available from: (http://www.uptimeinstitute.org)

Versteeg, H.K. \& Malalasekera, W. (1995). An introduction to computational fluid dynamics: the finite volume method, Longman, ISBN 058221884 5, London, UK.

Webb, B.W. \& Ma, C.F. (1995). Single phase liquid jet impingement heat transfer, Advances in Heat Transfer, vol. 26, (March 1995), pp 105-217, ISSN 0065-2717. 
Wolf, D; Incropera, F.P. \& Viskanta, R. (1993). Jet Impingement Boiling, Advances in Heat Transfer, vol. 23, (March 1993), pp 1-132, ISSN 0065-2717.

Zareifard, M.R;, Marcotte, M. \& Dostie, M. (2006). A method for balancing heat fluxes validated for a newly designed pilot plant oven. Journal of Food Engineering, vol. 76, no. 3, (October 2006), pp 303-312, ISSN 02608774.

Zheleva, I \& Kambourova, V. (2005). Identification of heat and mass transfer processes in bread during baking, Thermal Science, vol. 9, no. 2, (September 2005), pp 73-86, ISSN 0354-9836.

Zhou, W. \& Therdthai, N. (2007). Three-dimensional CFD modeling of a continuous industrial baking process, in: Da-Wen Sun (Ed.), Computational Fluid Dynamics in Food Processing, pp 287-312, ISBN 0849392861, retrieved from http://www.crcnetbase.com/isbn/9781420009217 


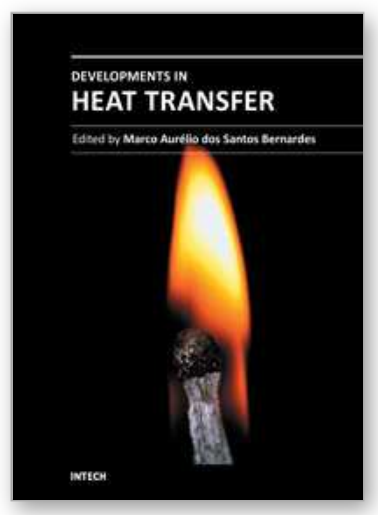

\author{
Developments in Heat Transfer \\ Edited by Dr. Marco Aurelio Dos Santos Bernardes
}

ISBN 978-953-307-569-3

Hard cover, 688 pages

Publisher InTech

Published online 15, September, 2011

Published in print edition September, 2011

This book comprises heat transfer fundamental concepts and modes (specifically conduction, convection and radiation), bioheat, entransy theory development, micro heat transfer, high temperature applications, turbulent shear flows, mass transfer, heat pipes, design optimization, medical therapies, fiber-optics, heat transfer in surfactant solutions, landmine detection, heat exchangers, radiant floor, packed bed thermal storage systems, inverse space marching method, heat transfer in short slot ducts, freezing an drying mechanisms, variable property effects in heat transfer, heat transfer in electronics and process industries, fission-track thermochronology, combustion, heat transfer in liquid metal flows, human comfort in underground mining, heat transfer on electrical discharge machining and mixing convection. The experimental and theoretical investigations, assessment and enhancement techniques illustrated here aspire to be useful for many researchers, scientists, engineers and graduate students.

\title{
How to reference
}

In order to correctly reference this scholarly work, feel free to copy and paste the following:

Harvey M. Thompson (2011). Heat Transfer and Thermal Air Management in the Electronics and Process Industries, Developments in Heat Transfer, Dr. Marco Aurelio Dos Santos Bernardes (Ed.), ISBN: 978-953307-569-3, InTech, Available from: http://www.intechopen.com/books/developments-in-heat-transfer/heattransfer-and-thermal-air-management-in-the-electronics-and-process-industries

\section{INTECH}

open science | open minds

\section{InTech Europe}

University Campus STeP Ri

Slavka Krautzeka 83/A

51000 Rijeka, Croatia

Phone: +385 (51) 770447

Fax: +385 (51) 686166

www.intechopen.com

\section{InTech China}

Unit 405, Office Block, Hotel Equatorial Shanghai

No.65, Yan An Road (West), Shanghai, 200040, China

中国上海市延安西路65号上海国际贵都大饭店办公楼 405 单元

Phone: +86-21-62489820

Fax: $+86-21-62489821$ 
(C) 2011 The Author(s). Licensee IntechOpen. This chapter is distributed under the terms of the Creative Commons Attribution-NonCommercialShareAlike-3.0 License, which permits use, distribution and reproduction for non-commercial purposes, provided the original is properly cited and derivative works building on this content are distributed under the same license. 